\title{
0 professor diretor de turma entre Portugal e o Brasil: do contexto de influência ao contexto da prática
}

\author{
The teacher director of class between Portugal and Brazil: from the context of \\ influence to the context of practice \\ El profesor director de clase entre Portugal y Brasil: del contexto de influencia \\ al contexto de la práctica \\ VAGNA BRITO DE LIMA \\ MARIA ZULEIDE DA COSTA PEREIRA \\ VIRGÍNIO ISIDRO MARTINS DE SÁ
}

\begin{abstract}
Resumo: O presente texto apresenta um recorte de um estudo desenvolvido no âmbito da pesquisa de doutorado, cujo objetivo consistiu em analisar a forma como os atores escolares, apropriaram-se do cargo do professor diretor de turma. A investigação compreendeu dois estudos de caso, um no contexto cearense, e outro, no norte de Portugal. Adotou-se como modelo de análise o ciclo contínuo de políticas (BOWE, BALL, GOLD, 1992; BALL, 1994), articulando-o com o modo de funcionamento díptico da escola (LIMA, 1998). Concluiu-se que os atores revelaram uma certa acomodação e conformismo, mostrando-se, contudo, convencidos da importância do PPDT para os estudantes.
\end{abstract}

Palavras-chave: Ciclo contínuo de políticas. Diretor de turma. Modo de funcionamento díptico.

Abstract: This text presents an excerpt from a study developed in the field of doctoral research, which aimed to analyze how the educational actors internalized the significance of being a class head-teacher in the context of Public Schools of Ceará State. The investigation covered two case studies, one in the Ceará context and the other in the north of Portugal context. As an analysis model, it was adopted the continuous policy cycle (BOWE, BALL, GOLD, 1992), articulated with the theoretical proposal for the study of the school as an educational organization (LIMA, 1998). It was concluded that the actors showed some accommodation and conformity, showing, however, they were convinced of the importance of PPDT for the students.

Keywords: Continuous cycle of policies. Class head-teacher. Diptic working mode.

Resumen: El presente texto presenta un recorte de un estudio desarrollado en el ámbito de la investigación de doctorado, cuyo objetivo consistió en analizar la forma como los actores educativos, se apropiaron del puesto del profesor director de clase. La investigación comprendió dos estudios de caso, uno en el contexto de Ceará, y otro en el norte de Portugal. Se adoptó como modelo de análisis el 
ciclo continuo de políticas (BOWE, BALL, GOLD, 1992), articulándolo con el modo de funcionamiento díptico de la escuela (LIMA,1998). Se concluyó que los actores revelaron un cierto acomodamiento y conformismo, mostrándose, no obstante, convencidos de la importancia del PPDT para los estudiantes.

Palabras-clave: Ciclo continuo de políticas. Director de clase. Modo de funcionamiento díptico.

\section{INTRODUÇÃO}

O presente texto apresenta um recorte de um estudo mais amplo desenvolvido no âmbito de uma pesquisa de doutorado. $\mathrm{O}$ estudo teve como objetivo analisar a forma como os atores da organização educativa - gestores, professores, alunos e pais - apropriaram-se das significações do cargo do professor diretor de turma, no contexto da escola pública estadual regular cearense.

No Brasil, o PPDT teve início no estado do Ceará, no ano de 2008, em 25 escolas estaduais de educação profissional, e, em 2010, foi ampliado por meio de "adesão" para as escolas de ensino regular da rede estadual. No percurso entre o início e o ano de 2017, observou-se uma rápida progressão, posto que, no referido ano, a rede de ensino já contava com esse projeto em 623 escolas, 5772 turmas e 5527 professores diretores de turma (SEDUC-CE, 2010).

A relevância do estudo consistiu na possibilidade de realizar uma análise da concretude da política educativa de gestão da sala de aula, nas escolas públicas estaduais regulares cearenses que aderiram ao PPDT, onde se buscaram identificar as (re)interpretações ou (re)contextualizações em relação ao cargo/função de diretor de turma instituído no sistema educativo português. Serviram de base, para o presente estudo, pesquisas realizadas em Portugal (LIMA, 1998, 2001; CASTRO, 1995; SÁ, 1997) e no Brasil (CHAVES; LEITE, 2012; COSTA, 2014), sobre a temática, bem como, outros autores que orientam a reflexão acerca da educação (BOWE; BALL; GOLD, 1992; BALL, 1989, 1994, 2014, 2016; BALL; MAINARDES, 2011; MAINARDES, 2007; AVELAR, 2016).

Reconhecendo-se a relevância de confrontar o "plano das orientações para a ação" com o "plano da ação"1, recorreu-se ao modelo de análise das organizações educativas/escolares, em suas múltiplas focalizações, na perspectiva de compreender o objeto estudado e suas diferentes dimensões combinando-o com a abordagem do ciclo contínuo de políticas formulado por Ball, Bowe e Gold (1992) e Ball (1994). Nesse contexto, procuramos compreender as (re) interpretações e (re)contextualizações pelas quais passou o PPDT, do "contexto da influência" ao "contexto da prática".

Ver Lima (2001). 
As reflexões realizadas suscitaram o seguinte problema de investigação: como é que os atores da organização educativa (gestores, professores, alunos e pais) se apropriaram das significações do cargo/função do diretor de turma, no contexto da escola pública estadual regular do estado do Ceará-Brasil, no período de 2011 a 2014?

\section{MODELOS DE ANÁLISE PARA A COMPREENSÃO DO OBJETO ESTUDADO}

A fim de interpretar os dados angariados no campo empírico, tomaramse como referência as concepções teóricas de Bowe, Ball com Gold (1992), Ball (1989, 1994, 2011, 2014), com foco no ciclo contínuo de políticas e os modelos de análise da escola como organização educativa. Assim, foi adotada a abordagem do "plano das orientações para a ação" e o "plano da ação" da escola como organização educativa, elaborado por Lima (1998, 2001), na perspectiva de analisar as diferentes significações acerca do Diretor de Turma reinterpretadas e/ou recontextualizadas na política educativa em atuação nas escolas públicas estaduais regulares no estado do Ceará-Brasil.

Em diálogo com Mainardes e Marcondes (2009, p. 304), Ball destacou que, "o ciclo de políticas é método. Ele não diz respeito à explicação das políticas. É uma maneira de pesquisar e teorizar as políticas. Algumas pessoas o leram e interpretaram como se eu estivesse descrevendo políticas e os processos de elaborá-las". Levando em conta esse pensamento, ao se refletir sobre a abordagem do ciclo contínuo de políticas criado por Bowe, Ball e Gold (1992), ampliado por Ball (1994), com reflexões proporcionadas através de interlocutores, como Mainardes e Marcondes (2009) e Avelar (2016), no Brasil, procurou-se construir uma primeira imagem com uma ideia de contextos enquanto trajetória, separados e inter-relacionados de forma subsequente, conforme se observa na Figura 1, a seguir. 


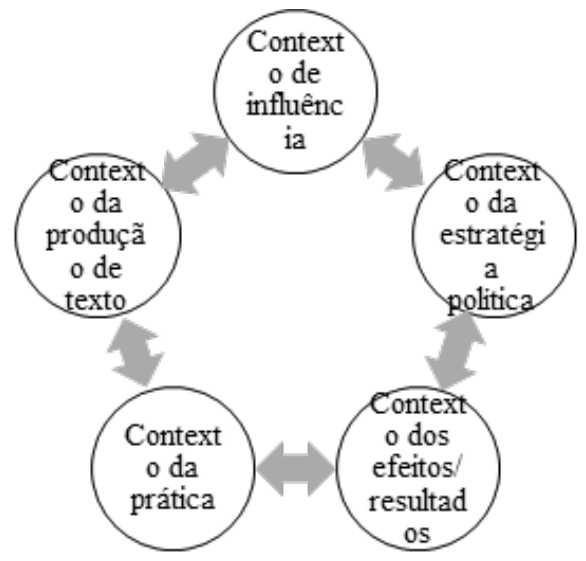

Fonte: LIMA, V. B. de (2017, p. 64).

Esta imagem procura destacar que a compreensão de cada contexto é relevante para a análise de política e se dá a partir das perguntas que o pesquisador levanta, em relação aos aspectos relacionados ao texto, à trajetória e à atuação da política analisada.

A partir das reflexões de Ball, assume-se a possibilidade de os contextos se apresentarem "aninhados". Através de seus diálogos com Mainardes e Marcondes (2009) e Avelar (2016), concebe-se a ideia de circularidade e sobreposição, entre os contextos da abordagem do ciclo contínuo de políticas, o que, na prática, significa a simultaneidade na atuação das políticas, o que pode suscitar outra imagem para apresentação desses contextos, como representado na Figura 2, a seguir:

Figura 2 - Imagem da versão “aninhada” dos contextos

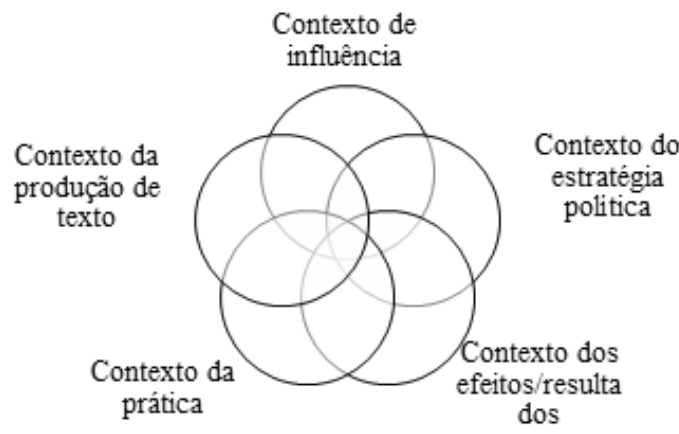

Fonte: LIMA, V. B. de (2017, p. 65). 
Para compreender o interior de cada contexto, procura-se entender as teorias, abordagens e imagens que ajudam a analisar os fenômenos, tanto no "plano das orientações para a ação" como no "plano da ação" (LIMA, 2001). Para tal, é imperativo que, por um lado, se invista no exercício compreensivo que "de um ponto de vista racional-legal, nas escolas opera-se por referência a estas orientações normativas; um problema é resolvido a partir do momento em que lhe é conferido solução formal" (LIMA, 1998, p. 170). Por outro lado, faz-se necessário considerar que as orientações são recontextualizadas, e recriadas, no processo de atuação, nos contextos de nível meso e micro, na escola, conforme os objetivos, interesses e estratégias dos atores envolvidos. Dimensão esta que Lima $(1998,2001)$ designa 'infidelidade normativa', e Ball (1989), 'micropolítica'.

\section{METODOLOGIA/PROCEDIMENTO}

A abordagem teórico-metodológica que norteou a presente investigação possui natureza qualitativa, de cunho analítico interpretativo. Os dados recolhidos, predominantente qualitativos, apresentam riqueza de detalhes descritivos, concernentes às pessoas, locais e conversas e exigem uma complexa análise.

Foram realizados dois estudos de caso, em contextos diferentes, desenhando-se, desse modo, um estudo de caso único, integrado por duas unidades de análise; e outro estudo de caso único, holístico, com uma única unidade de análise, um em cada locus estudado, Brasil e Portugal. Tal opção resultou da articulação entre as asserções sobre o estudo de caso de Stake (2012) e Yin (2010). Neste texto. mobilizamos apenas os dados recolhidos no contexto brasileiro.

Os instrumentos adotados para a coleta de dados consistiram em pesquisa bibliográfica e documental, levantamento por meio de questionário, visitas de observação não participante, notas de campo e entrevistas semiestruturadas.

Entre SEDUC-CE e CREDE, foram realizadas cinco entrevistas: coordenação estadual (2010-2014) (1), coordenação estadual 2015 (1), idealizador do PPDT (1), consultor externo (1) e coordenação regional - CREDE (1).

No andamento da pesquisa, foi realizado um levantamento junto às CREDE e SEFOR, com o objetivo de identificar a escola estadual de ensino regular com mais tempo de adesão ao PPDT, em todas as turmas no estado do Ceará. Diante do resultado desse levantamento, selecionou-se a unidade de análise, EB, para a realização do estudo de caso, onde foram realizadas visitas de observação, análise dos documentos internos da escola e realização de entrevistas. Foram realizadas oito entrevistas: com a diretora geral (1), com a coordenadora do PPDT na escola (1), com professores (2), com alunos (2), com pais/mães (2). 
Para efeito de identificação, nos excertos das falas dos atores educativos entrevistados no campo empírico, segue o Quadro 1, com a discriminação e a sigla atribuída a cada sujeito, com o intuito de preservar o anonimato das pessoas entrevistadas.

\section{Quadro 1 - Legenda das siglas para identificação das falas dos sujeitos entrevistados}

\begin{tabular}{|l|c|}
\hline \multicolumn{1}{|c|}{ Sujeito } & Siglas \\
\hline BRASIL & \multicolumn{2}{|l}{} \\
\hline SEDUC-CEARÁ & PCEPPDT \\
\hline Primeiro Coordenador Estadual do Projeto Professor Diretor de Turma & CEPPDT \\
\hline Coordenador (a) Estadual do Projeto Professor diretor de Turma & CRPPDT \\
\hline Coordenador (a) Regional do Projeto Professor diretor de Turma & EEB \\
\hline Especialista em Educação Brasileira membro da ANPAE & CEP \\
\hline Consultora Externa Portuguesa do Projeto Professor Diretor de Turma & \\
\hline ESCOLA BRASILEIRA & DGEB \\
\hline Diretor (a) Geral na Escola Brasileira & CPPDTEB \\
\hline Coordenador (a) do Projeto Professor Diretor de Turma na Escola Brasileira & PDTEB \\
\hline Professor (a) Diretor de Turma na Escola Brasileira (1 e 2) & PMEB \\
\hline Pai/Mãe na Escola Brasileira (1 e 2) & AEB \\
\hline Aluno (a) na Escola Brasileira (1 e 2) & \\
\hline PORTUGAL - ESCOLA PORTUGUESA & DEP \\
\hline Diretor (a) da Escola Portuguesa & CDTEP \\
\hline Coordenador (a) dos Diretores de Tuma na Escola Portuguesa & PDTEP \\
\hline Professor (a) Diretor de Turma na Escola Portuguesa (1 e 2) & EEEP \\
\hline Encarregado de Educação na Escola Portuguesa (1 e 2) & AEP \\
\hline Aluno (a) na Escola Portuguesa (1 e 2) &
\end{tabular}

$* \mathrm{ANPAE}^{2}$

Fonte: LIMA, V. B. de (2017, p. 103-104).

2 Uma das primeiras associações brasileira da sociedade civil organizada no campo da educação, fundada em $1961 \mathrm{com}$ outra nomenclatura, passando por diferentes transformações ao longo dos anos, desde o ano de 1996 mantém a atual denominação. Para Benno Sander (2007, p. 1-2), "A ANPAE foi concebida com a missão de lutar pelo exercício do direito à educação de qualidade para todos, através de sua participação na formulação de políticas públicas de educação e na concepção e adoção de práticas de gestão democrática, alicerçadas nos princípios e valores da solidariedade e justiça social e da liberdade e igualdade de direitos e deveres na educação e na sociedade". Disponível em: < https://www.anpae.org.br/website/documentos/ estudos/estudos_01.pdf>. Acesso em: 6 ago. 2019. 


\section{O PROFESSOR DIRETOR DE TURMA ENTRE O "CONTEXTO DA INFLUÊNCIA" E O "CONTEXTO DA PRÁTICA"}

\section{O DIRETOR DE TURMA NA ESCOLA PORTUGUESA}

Embora a criação do cargo 'Diretor de Turma', com essa nomenclatura, entre em vigor com a publicação do Estatuto do Ciclo Preparatório do Ensino Secundário $^{3}$, publicado em 9 de setembro de 1968, a origem dessa estrutura de gestão intermédia, no sistema escolar português, remonta ao 'Diretor de Classe', criado pelo decreto de 14 de agosto de 1895, que regulamenta a reforma Jaime Moniz (CASTRO, 1995; SÁ, 1997). Para Sá (1997, p. 24), esse órgão de gestão intermédia passa por "diferentes metamorfoses" "até cristalizar na figura do director de turma".

\section{Figura 2 - Principais "metamorfoses" do diretor de turma no sistema educativo português}

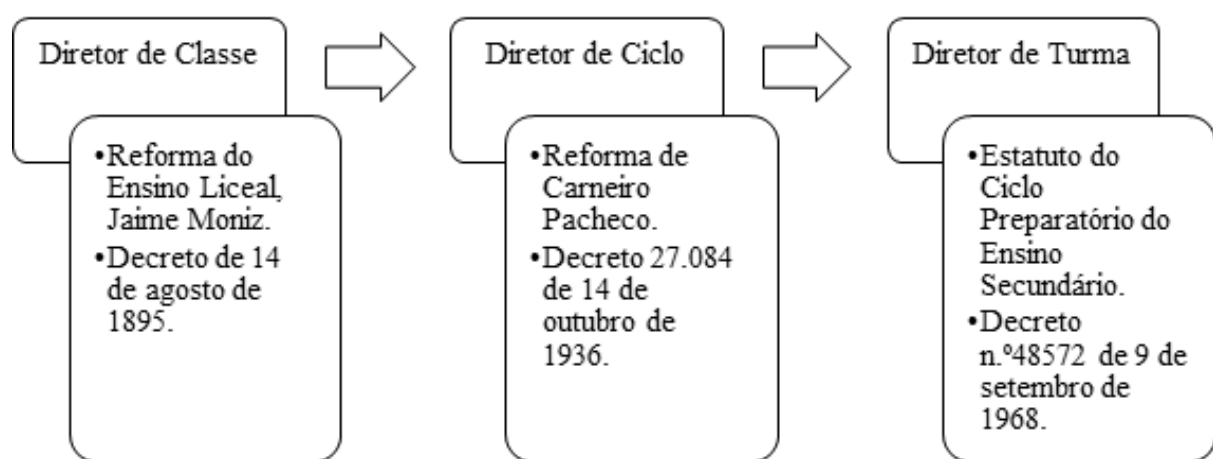

Fonte: Sá (1997, p. 24).

A criação do diretor de turma, em 1968, insere-se no contexto da "emergência da escola de massas" (SÁ, 1997), na educação portuguesa, contexto esse em que "a rápida expansão do sistema educativo escolar resultou da conjugação da vontade política, da conjuntura económica e da procura social da educação" (SÁ, 1997, p. 44).

3 Estrutura e organização da educação pública portuguesa. 


\title{
O PPDT NA EDUCAÇÃO CEARENSE CONTEXTO DE INFLUÊNCIA
}

À guisa de compreensão das influências no processo de construção do PPDT, destaca-se o extrato da entrevista com uma coordenadora regional do projeto professor diretor de turma (CRPPDT) sobre a origem da referida política educativa no âmbito das escolas públicas estaduais cearenses:

\begin{abstract}
Até onde eu sei, porque foi algo que nunca foi tão divulgado, né? Mas até onde a gente ficou sabendo na função de coordenador regional, quando começamos em 2010, é que o projeto diretor de turma, ele chega aqui no estado do Ceará por volta de 2007, né? Ele foi disseminado, a ideia foi disseminada por meio da ANPAE na pessoa da professora (EEB), e, e da professora (CEPPPDT), a professora diretora de turma de Portugal. O projeto professor diretor de turma foi apresentado no congresso da ANPAE em 2007, se eu não me engano! E aí, ela teve a ideia, ela foi inicialmente testada em três escolas da rede municipal a nível de Fundamental... depois, essa experiência, ela chegou ao conhecimento da SEDUC quando a professora ... (EEB) foi conversar com a professora da CODEA para que pudesse experimentar o projeto piloto em algumas escolas da rede estadual de Fortaleza (CRPPDT, 2015).
\end{abstract}

Analisando o extrato da fala da entrevistada, pode-se considerar que a narrativa discursiva, tal como a de performance pública, de uma Especialista em Educação Brasileira (EEB), e de relevante influência política no estado do Ceará, contribuiu para a negociação da construção da política em estudo. Por conseguinte, comparando a fala acima com o texto escrito no folder de divulgação, quando se menciona a gênese do PPDT, percebe-se uma assimilação do discurso empregado nos documentos oficiais da política em destaque:

O Projeto Professor Diretor de Turma teve sua origem, aqui no Brasil, por ocasião do XVIII Encontro da ANPAE - Seção do Ceará, no ano de 2007, quando foi apresentada a experiência das escolas públicas portuguesas. Baseados nessa apresentação, gestores educacionais dos municípios de Eusébio, Madalena e Canindé iniciaram um projeto piloto em três escolas (SEDUC-CE, 2010, p. 1).

Cabe, ainda, compreender que algumas políticas 'feitas' que se materializam nas escolas são 'escritas' pelo governo, ou pelas agências e/ou investidores, influentes nos contextos locais, ou nacionais, envolvendo negociações, contestações e/ou lutas entre os grupos de formuladores de políticas, que podem estar fora da máquina formal de elaboração de políticas oficiais (BALL, 2016). 
No extrato discursivo da professora Especialista em Educação Brasileira (EEB), à qual se atribui a ideia de trazer o PPDT para o Ceará, quando questionada sobre a gênese de tal política educativa - O que é o PPDT em andamento nas escolas públicas estaduais do Ceará? - a referida especialista argumenta que

O projeto tem toda uma história, para termos chegado aí. Primeiro, eu agora tenho 76 (setenta e seis) anos. Então, da sala de aula eu estou afastada, mas como eu fui secretária, é, saí de lá em noventa e quatro (1994). Então, eu me dediquei tanto, e eu acho que eu tenho obrigação de passar isso adiante. Quando eu era estudante, eu sempre estudei em colégio católico, o Dorotéia aqui no Ceará e o Sacré Coeur de Jésus no Rio de Janeiro. Em todos esses colégios, a maioria deles, maioria era europeia. Então, o colégio, o próprio colégio cearense, ele é um colégio se eu não me engano, francês, e, todos esses tinham a mestre de classe. E a gente nem dá valor, porque estudante vai no rumo né?! No caminho que a gente é colocada. Mas eu sempre notei que a mestre de classe era uma pessoa mais próxima da gente, e, que nós éramos avaliados pelas atitudes, pelo comportamento, pela dedicação aos estudos, era uma avaliação assim conceitual. Mas ela fazia também a coordenação daquela turma, isso eu senti aqui nas Dorotéias e senti lá no Rio... (EEB, 2016)

Em seguimento, na resposta à mesma pergunta, a entrevistada segue com sua argumentação:

Fui secretária da educação e nunca pensei de fazer algo semelhante na escola pública, porque a escola pública é uma distância tão grande da escola particular que a gente... e depois a miséria de dinheiro é tão grande que qualquer coisa que a gente pensasse, a gente até tirava, isso aqui é para a escola particular, escola pública é outra coisa. Nada! A escola pública não é pior não! Precisa ser até melhor que a escola particular, viu! Então, eu fui lá para Portugal, assisti a defesa de tese da... ela era antes diretora de escola aqui, e eu fui fazer contato com a ANPAE! Fazer um contato com a Universidade do Minho porque eu conhecia o Carlos Estevão! Eu tinha passado por lá uns anos atrás e já tinha saído, eu acho o Virgínio que escreveu... aí eu vi exposto lá a publicação na mesa, na universidade, no Instituto de Educação... aí eu peguei e comprei... quando eu cheguei em casa notei, é o mestre de classe! (EEB, 2016)

Ao contrário de outras políticas educativas, oriundas das agências de elaboração de políticas com interesses transnacionais, e disseminação em redes políticas em âmbito nacional (BALL, 2014), quando se faz a análise dos extratos discursivos - antes citados - dos atores envolvidos na atuação, pode-se verificar nesses depoimentos que as influências são advindas do poder local, no caso da política estudada. No entanto, pode-se perceber, também, influências das experiências particulares, e das experiências externas. 
Ao se perguntar à Consultora Externa Portuguesa (CEP) como se deu o processo de "implementação" do PPDT no estado do Ceará, ela destaca:

Foi através da... (EEB), secretária de estado do Ceará, [...] conhecia cá em Portugal, ela viu o meu trabalho como diretora de turma, mas, mais dentro da área de gerir os alunos, de gerir a turma, de gerir as problemáticas que existiam dentro da turma. Ela assistiu a algumas aulas minhas e ficou encantada, aí eu levei o projeto para um congresso de educação da ANPAE em abril de 2007. Três escolas quiseram ser escolas piloto, que foi Madalena, Canindé e uma outra... Eusébio. Pronto, e passados 3 meses, mesmo sem orientação quase nenhuma, só com a apresentação que eu fiz do projeto, os diretores das escolas foram aplicando, não foi com orientação, portanto, foram aplicando daquilo que ouviram e viram resultados muito positivos em relação aos alunos. Então a secretaria da educação do Ceará chamou-me, eu expus o projeto e, foi-me pedido que ficasse, que fizesse uma formação a nível de vários professores, que seriam professores multiplicadores. (CEP, 2016)

Nesse 'contexto de influência', ao explorar as narrativas discursivas dos diferentes sujeitos em atuação na cena da política educativa do PPDT, percebemse convergências no sentido de identificar as principais 'fontes inspiradoras' para a elaboração do PPDT, e divergências, nos sentidos imbricados na ação de cada indivíduo, posto que há os interesses particulares de cada ator no processo de interpretação, tradução e recriação da política em ação.

\section{CONTEXTO DA PRODUÇÃO DO TEXTO}

Para Bowe, Ball e Gold (1992, p. 21), "a política não é feita e terminada no momento legislativo, ela evolui nos textos que a representam, e os textos devem ser lidos em relação ao tempo e ao local específico de sua produção"4 (tradução nossa). Desse modo, é comum que o texto da política passe por interpretação, tradução e ou interpretação de interpretações, nas disputas pelo controle de representação dos sujeitos, nas arenas de atuação.

No excerto abaixo, de uma entrevista, percebe-se um exemplo habitual no campo das políticas educativas, ou seja, "uma concepção linear de políticas impostas para as escolas de cima para baixo (top-dawn)" (BOWE; BALL; GOLD, 1992; BALL, MAGUIRE; BRAUN, 2016), geradora de tensões entre a arena da prática e o contexto de elaboração do texto:

4

"Policy is not done and finished in the legislative moment, it evolves in and through the texts that represent it, texts have to be read in relation to the time and the particular site of their production" (BOWE; BALL; GOLD, 1992, p. 21). 
De início eu gostei da proposta de cuidar dos meus alunos, de ter uma relação mais próxima com os meninos, ter aula de formação para cidadania. Mas nada me preparou para o que viria, logo quando eu e meus amigos chegamos lá de Fortaleza, o que a gente recebeu foi fichas, fichas e mais fichas, todas em PDF. Numa linguagem que muitas vezes estava longe da nossa realidade, porque os instrumentais que nos foram apresentados eram instrumentais da realidade das escolas portuguesas. Embora, a nossa escola de educação profissional, ela tivesse uma proposta mais ou menos alinhada a essa filosofia, mas estava muito distante da nossa carga horária, da nossa situação funcional, do preparo teórico metodológico, que os professores portugueses, imagino que tenham, e que, nosso caso não. (CRPPDT, 2015).

Embora seja natural o estranhamento em relação ao primeiro contato com os documentos - 'instrumentais da realidade das escolas portuguesas' e ou 'fichas' - até então desconhecidos pelos professores brasileiros, esboçou-se uma resistência inicial à inovação. Contudo, observa-se uma receptiva acomodação da proposta a ser trabalhada:

Mas mesmo sem conhecer, mesmo sem a gente ter esse preparo todo, a gente começou o trabalho, tentando entender como era que funcionava, como era que fazia a ficha biográfica, para que ela servia. A gente foi se perdendo naquele mundaréu de fichas! A gente ansiava pela presença da professora... (CEP) na nossa escola [...] Porque eu sempre parti do pressuposto, que eu só faço alguma coisa quando eu compreendo o que eu tenho que fazer, então eu não entendia como era que em uma carga horária de três horas eu ia ter que cumprir todas aquelas funções e ainda sem entender qual era a função daquele mundaréu de fichas. Três meses depois a professora (CEP) veio na escola e a vinda dela foi um divisor de águas na minha vida [...] ela mudou a minha vida profissional [...] (CRPPDT, 2015).

A partir da fala apresentada acima, pode-se perceber que, inicialmente, os textos foram levados prontos para o contexto da prática, e que, face às leituras ativas, as resistências e negociações motivaram a readaptação e reescrita dos textos. Isso também pode ser observado na citação que segue:

$\mathrm{Na}$ realidade, quando ele começou em 2008, não havia nenhum documento em 2008! Os únicos instrumentos que existiam eram os instrumentais que foram trazidos de Portugal, que até então não tinham sido submetidos a uma adequação, a um estudo, a uma reorganização ou uma reformatação mais consistente, né?! A professora... (técnica SEDUC) e a professora (CEP) até andaram dando uma olhada, para ver a grosso modo quais seriam as possíveis adaptações, e, existia meio que pontualmente algumas apresentações de slides que norteavam aí, o trabalho dos educadores das nossas unidades de ensino. (PCEPPDT, 2015).

No 'contexto da produção do texto', é oportuna a compreensão em relação aos tipos de textos relativos a políticas. Nessa direção, o texto de política oferece possibilidades restritas para a interpretação e tradução criativa, pelos 
atores, no processo de encenação da política, por se tratar de uma linguagem técnica, estabelecimento de metas previamente definidas, realização de testes padronizados de aprendizagem e programas de estudos. São textos legíveis (readerly), que sugerem possibilidades limitadas de interpretação. Nesse sentido, os textos do tipo escrevíveis (writerly) convidam os sujeitos a leituras e releituras ativas, autoconscientes, à participação, à cooperação, e a ser coautor. Contudo, essa liberdade tem certo grau de interpretação e leitura, ou seja, não é qualquer liberdade aberta à ação. (BOWE; BALL; GOLD, 1992; BALL, 2016). política e o contexto da prática, - "tinha muita coisa que a gente já fazia, que o diretor de turma tinha que fazer e o $\mathrm{SIGE}^{5}$ já estava pronto" - , bem como

Nas narrativas dos atores sociais entrevistados (gestores, professores, alunos e pais, coordenadores regional e estadual do PPDT, consultores e idealizadores), percebeu-se interação, intersecção e ou sobreposição entre a a decodificação e recodificação do texto - "a gente adequou o que pôde de instrumentais" - . Isto ocorre porque, de acordo com Ball (1994, p. 19), "a tradução das simplicidades cruas e abstratas dos textos políticos em práticas interativas e sustentáveis de algum tipo envolve pensamento de produção, invenção e adaptação" (tradução nossa).

\section{CONTEXTO DA PRÁTICA}

A arena de prática/plano da ação - por mais que se configure o contexto para o qual a política foi pensada - não quer dizer que essa política será meramente implementada/reproduzida, uma vez que ela estará aberta à interpretação, tradução e recriação, nos termos dos atores envolvidos, razão porque, a partir dos seus entendimentos, valores e interesses, essas políticas são contestadas e 'recriadas' (BOWE; BALL; GOLD, 1992), transformando a escola também num espaço de 'produção’ de regras (LIMA, 2001).

$\mathrm{O}$ argumento participativo dos envolvidos está implícito no discurso daqueles que se investem de autoridade, em relação à política, ou seja, os atores imbuídos na formulação e ou reformulação da política. O texto que segue contém elementos para apoiar esta análise:

5 O Sistema Integrado de Gestão Escolar trata-se de um sistema informatizado de acompanhamento acadêmico de todos os alunos das escolas públicas estaduais do Ceará. Tal como, monitoramento e controle da lotação de professores, diretor de turma, estrutura física das escolas, organismos colegiados (grêmios estudantis e conselhos escolares, funcionários terceirizados e demais projetos e programas em andamento na rede de ensino).

6 "The translation of the crude, abstract simplicities of policy texts into interactive and sustainable practices of some sort involves production thought, invention and adaptation" (BALL, 1994, p. 19). 
A secretaria de educação teve o cuidado de primeiro encaminhar para cada coordenadoria, colocar à disponibilidade das comunidades de cada coordenadoria essa chamada pública, para que elas pudessem se apropriar, fazer uma leitura, compreender a proposta. E aí, como consequência socializar essa proposta junto a todos os gestores escolares, para que eles pudessem se apropriar da mesma, e, consequentemente disseminá-la nas escolas apresentando a proposta para os professores, fazendo com que os educadores de certa forma, aderissem ou não. Então, o fluxo se deu dessa forma, Secretaria de Educação do Estado - CREDE - Escola. Então, o foco da secretaria, era fazer primeiro com que todos esses segmentos se apropriassem da proposta, e aí, não foi uma imposição, foi uma proposta de adesão, onde as escolas poderiam optar por se queriam ou não fazer a adesão, certo?! (PCEPPDT, 2015)

A narrativa de descentralização sugere leitura, apropriação, interpretação, tradução, participação e aceitação, ou não. Contudo, nesse fluxo 'descentralizado' - 'Secretaria de Educação do Estado - CREDE - Escola' - descontextualizase, em um espaço, e se recontextualiza, em outro, e se passa por contestação e conformidade, nos contextos interrelacionados do ciclo da política em ação.

Analisando a fala de um sujeito com experiência no PPDT na sala de aula, observam-se algumas contestações em relação ao discurso da apropriação por todos os segmentos. Ao se perguntar ao Professor Diretor de Turma da Escola Brasileira (PDTEB) entrevistado, sobre sua iniciação no PPDT, ele destaca:

Já chegou em forma de capacitação, porque eu sou uma das primeiras do grupo, sou a mais velha (risos)! É porque assim, quando eu tomei conhecimento do projeto em 2010, eu já fui intimada para uma capacitação porque eu iria ser diretora de turma. É um ultimato, chegou você tem que ir! Lógico, logo que nós chegamos lá, naquele primeiro momento foi aquele impacto! "Poxa eu vou dar conta de tudo isso, eu também vou dar aula, eu vou dar conta de tudo isso? No primeiro momento você já pensa assim... "Eu vou dar conta?" É muita responsabilidade! Então, eles chegaram e disseram assim: "o projeto é teu, toma, vai dar conta, eu acredito em você". (PDTEB - 1, 2015)

Para além da contestação do discurso de descentralização e apropriação da proposta do PPDT nos diferentes segmentos da estrutura organizacional da secretaria da educação do estado do Ceará, defendido no excerto anterior (PCEPPDT, 2015), percebe-se a interpretação da política educacional em relação às influências e textos assimilados pelos atores, nos contextos de influência e produção de texto, como se pode comparar com o trecho encontrado no folder/ panfleto de divulgação: "O Projeto desenvolve-se numa atmosfera educativa favorável, tendo por princípios básicos os quatro pilares da educação de Jacques Delors: Aprender a conhecer, aprender a fazer, aprender a viver juntos e aprender a ser" (SEDUC-CE, 2010, p. 6). 
Em outra direção, destaca-se a fala do (a) Coordenador (a) do Projeto Professor Diretor de Turma, na Escola Brasileira (CPPDTEB), que afirma ter havido, inicialmente, uma multiplicação das metodologias empregadas no PPDT - por parte da CEP - na ocasião da implantação da política educativa em tela, nas Escolas Estaduais de Educação Profissional. Entretanto, ao tratar das escolas regulares, locus em que este estudo procura compreender a trajetória da política educativa, na mesma fala, o (a) referido (a) coordenador (a) afirma:

$\mathrm{Na}$ escola na qual eu trabalhei a (EEEP), a professora... (CEP) esteve conosco, foi uma tarde longa, até o anoitecer, e ela apresentou todos os instrumentais, o objetivo de cada instrumental fez uma simulação das reuniões: da reunião diagnóstica, da reunião bimestral. E, falou da importância do registro desses documentos, da construção do dossiê, da vida do aluno ali documentada e ali sempre ao nosso alcance. Falou também da importância da visita domiciliar. Essa visita domiciliar, ela é muito boa! Você ir à casa do aluno, visitar o pai, conhecer a realidade dele. Nessa escola nós tínhamos esse compromisso de irmos realmente. Mas, na escola regular, já é bem diferente, nós não conseguimos ir à casa de todos os nossos alunos (CPPDTEB, 2015).

É no 'contexto da prática' que os atores escolares consideram que 'a parte burocrática' dificulta que o PPDT alcance melhores efeitos, eles argumentam que os objetivos do mesmo são interessantes e buscam "conduzir a turma do início ao fim do ano", ou seja, evitar a evasão escolar. Contudo, as exigências administrativas parecem comprometer o sucesso do projeto:

Eu sou professor de matemática do terceiro da noite... o projeto ele tem objetivos bem interessantes, buscando mecanismos como conduzir a turma do início ao fim do ano... e até mesmo estudar os problemas dos alunos, que muitas vezes trazem para a sala de aula, ele visa conhecer um pouco mais não só o aluno, mas a família, para que a gente possa prevenir certos comportamentos em sala de aula, na medida do possível, ir dentro do acontece. Ao mesmo tempo que o projeto tem essa visão, bem ampla, esse objetivo bem claro, a gente ainda não tem tanto êxito na parte burocrática [...] A parte burocrática, creio eu que se nós tivéssemos um pouco mais de tempo de nos sentar com a família desse aluno surtiria mais efeito. (PDTEB - 2, 2015)

Outro aspecto que tem sido destacado pelos atores envolvidos na política educativa é a importância da interação com as famílias dos alunos. 


\section{CONTEXTO DOS RESULTADOS/EFEITOS}

$\mathrm{Na}$ esteira do pensamento de Ball (1994), uma das dificuldades em discutir os efeitos se dá, possivelmente, por se fazer confusão entre efeitos gerais e específicos.

Os efeitos específicos de uma política podem ser limitados; entretanto, os efeitos gerais de um conjunto de políticas de diferentes tipos podem ser diferenciados.

Nessa direção investigada, nota-se que, ao se analisar o excerto da fala de um (a) PDTEB, destaca-se como resultado o comportamento do aluno dentro da escola, a diminuição da evasão escolar e a participação, a saber:

É cinco anos de projeto! O que nós observamos de mudança aqui dentro, estou falando aqui dentro da... (EB) é enorme! Porque diminuiu a evasão, comportamento, a participação em si, melhorou demais! [...] Eles sabem que eles estão sendo mais monitorados. Assim, de certa forma, "não eu não vou fazer tal coisa porque eu sei...", porque antes eles tinham aquela ideia "eu posso fazer o que eu quiser, que não vai acontecer nada"! Então, com o projeto não, como eles (alunos) são mais observados eles têm o maior cuidado. De certa forma, eles têm "um pai ou uma mãe" observando... Até no recreio, até no intervalo a gente tem aquele contato... (risos) (PDTEB - 1, 2015).

Nas entrevistas com o Aluno (a) na Escola Brasileira (AEB), identificase uma assimilação positiva, em relação à representação do PDT, nas relações aluno/ escola/família. Nessa vertente, os AEB 1 (2015) consideram:

Eles não se preocupam só na escola né?! A gente ver que eles se preocupam também fora da escola, quando a gente falta eles procuram saber se aconteceu alguma coisa, se a gente estava doente e tal! Se está passando por alguma coisa, algum problema, ele visita a nossa casa se puder ele ajuda... (AEB 1, 2015)

Em outro excerto de entrevista, também com AEB, confirma-se essa identificação personalizada na imagem do PDT, como um amigo, um conselheiro, um "pai", para além das questões que envolvem o fazer pedagógico:

Ele representa a nossa sala, porque geralmente o professor, ele vai defender o aluno, vai ajudar, ele conhece os alunos pessoalmente, ele sabe o problema que cada aluno passa e isso ajuda muito. O nosso em particular, a gente tem como um pai né, um amigo, como por exemplo, ele nos dar conselhos, ele às vezes nos dar, como ele fala: um cascudo! (Risos) Eu gosto deste projeto diretor de turma! Ajuda bastante! Além de diretor de turma, no caso, o professor acaba se tornando nosso amigo. (AEB 2, 2015) 
Entretanto, percebe-se que o olhar individualizado do PDT, para com seus alunos, é direcionado, principalmente, para a manutenção do vínculo do aluno com a escola, na perspectiva da garantia da permanência e, consequentemente, na redução da evasão, sem desconsiderar a ética do cuidado mencionado pelos alunos.

A narrativa do (a) Pai/Mãe na Escola Brasileira (PMEB), vai na mesma direção:

Para mim, eu acho que o professor de turma, ele é tipo assim um pai... tá ali preocupado, ele vai... se o aluno tá com algum problema, ele vai saber, ele vai procurar saber o porquê, o que tá acontecendo, ele chama os pais para conversar por isso que eu acho excelente... para mim pessoalmente, eu acho excelente... (PMEB, 2015).

Os atores, AEB e PMEB, destacaram a dimensão do acompanhamento permanente da frequência e do rendimento escolar, o que pode ser interpretado como um controle mais individualizado para cada aluno, e suas famílias... Conforme se pode comparar com a fala do (a) Diretor (a) Geral, na Escola Brasileira (DGEB), a problemática da evasão escolar se configura como o efeito mais apontado pelos sujeitos:

O mais impactante é a evasão, assim, a redução da evasão. Se eu não me engano, em 2011 era o segundo ano do projeto, que foi quando nós passamos a participar do Jovem de Futuro que foi o ano base para nossas medidas, nós estávamos com 12\% de alunos com evasão, e nossa meta era reduzir $40 \%$. E o ano passado a gente já inclusive chegamos a reduzir $40 \%$ da nossa evasão... é uma coisa que eu acho que a gente não vai conseguir baixar muito, até porque nós temos um turno da noite, que é um turno muito grande e a maioria desse turno da noite, é aquela questão do aluno trabalhador, maior de idade que está aqui hoje, acabou o emprego ele vai pra Fortaleza ele vai pra São Paulo.

\section{Nesse sentido, a DGEB acrescenta:}

São pais de família, tem que sair à procura de emprego, mas o projeto ajudou muito aí nessa parte, nessa questão da gente conseguir ultrapassar inclusive a meta, que era $40 \%$ e nós já conseguimos $42 \%$ da evasão. Porque como eu te disse lá no início, no meu caso como diretora e coordenadoras, temos como detectar aquele aluno que está faltando há uma semana, há duas semanas. Nós temos aqui professores que passam em 27 salas, Filosofia com 1 hora. Então, ele chega ali, pensa que aquele aluno veio na aula dele, mas não sabe se nas outras aulas ele está vindo. Então, se não fosse o professor diretor de turma para detecta a tempo de a gente ir na casa deste aluno e a gente procurar a família... 
Analisou-se no 'contexto dos resultados/efeitos', merecendo mais destaque como efeito do PPDT, no âmbito da educação cearense, a interação da família com a escola, na perspectiva da redução da evasão, a melhoria dos rendimentos, embora não se tenham encontrado dados oficiais que revelassem tal efeito para além dos discursos dos atores envolvidos.

\section{CONTEXTO DA ESTRATÉGIA POLÍTICA}

Nesse contexto, a preocupação é com a identificação de um conjunto de atividades políticas e sociais que consigam resolver mais eficazmente as desigualdades e injustiças produzidas, nas situações de lutas por interesses individuais, no âmbito das políticas analisadas (BALL, 1994).

$\mathrm{Na}$ perspectiva de analisar as estratégias delineadas pelo PPDT, nas escolas cearenses, destaca-se a narrativa do (a) CPPDTEB (2015):

Foram muitas adequações, porque o que a (CEP) trouxe de instrumentais... eram vários registros, era realmente um processo muito burocrático, muito! Então, ao longo do tempo, na escola profissional foi assim como ela recebeu, digamos assim a dona do projeto! A gente tentava seguir à risca aqueles instrumentais! Mas, quando se passou para o segundo ano, aquilo que a gente achava que poderia mudar, já mudava. Algo muito difícil de você tentar realizar na data precisa é aquela reunião bimestral. A reunião diagnóstica não! A gente consegue dentro de uma data precisa, agora a bimestral... porque vem num atropelo de afazeres de final de bimestre, correção de provas, entrega de notas né! Então, sempre acontecia de uma forma bem atropelada! Sim, na marra mesmo! Tentando reunir os professores do Conselho de Classe, tentando chamar os pais para aquele momento [...] foi adaptado [...], nós não conseguimos realizar a reunião bimestral com a reunião do Conselho de Classe. Devido à nossa realidade! São cerca de cinquenta e sete turmas, cinquenta e três têm o projeto [...].

Compreende-se que as estratégias delineadas no processo de adequação são resultadas das lutas dos grupos de interesses, na atuação no contexto da prática (professores, diretores, coordenadores escolares, pais e alunos), em decorrência dos conflitos de nível micropolítico que mobilizam os atores na arena de atuação, na relação com todos os envolvidos.

Outra estratégia que pode ser destacada é o direcionamento da política educativa em análise para o acompanhamento dos resultados de aprendizagem e avaliação dos alunos, como destaca o PDTEB (2015): 
Eu sou diretor de turma do terceiro ano, e, a gente hoje no Brasil a gente fala muito do ENEM né?! Essa dificuldade, porque tem gente no interior que não tem condições! E implantar na mente do aluno essa visão hoje, de que pode ser alguém na vida e buscar algo na vida. [...] Nós temos essa função! Vamos dizer, levar esse cara conosco aqui né?!(gesto de braços dados). Então, esse projeto é muito interessante porque ele mostra, ele tenta mostrar uma visão diferente numa sociedade corrompida que nós temos.

Percebe-se que o PDTEB é responsável por corporificar, na consciência dos alunos, a importância da cultura das avaliações de larga escala existente no país. Pode se destacar ainda a responsabilização do professor, como gestor da sala de aula, com a função de articular os processos de gestão da turma concernentes às questões pedagógicas - com os demais professores da turma; as relações interpessoais entre os alunos da turma; e a interação da escola com a família. Aspecto que se aproxima do que Sá (1997), em seu estudo sobre o diretor de turma na educação portuguesa, denomina gestão intermédia. Neste sentido, o (a) CPPDTEB (2015) identifica, como uma das estratégias do PPDT:

Bem, ele (PPDT) tenta colocar em cada sala de aula um gestor né! Alguém que tenha um olhar mais afinado para aquela turma, que possa acompanhar melhor, ver aquilo que enquanto o diretor, que enquanto o coordenador vê de uma maneira geral, o professor vai ver de perto... que é o aluno, que é a presença dele, que é a participação dele em sala de aula, a atuação do professor em sala de aula. E, principalmente, eu acredito que o professor de turma ele tem um foco muito voltado para a evasão escolar que é um caso gravíssimo que hoje nós enfrentamos na escola pública, muito grave. (CPPDTEB, 2015)

Em outro momento, o (a) CPPDTEB (2015) evidencia, em seu discurso, as expectativas normativas atribuídas à figura do PDT:

Contribui sim, se ele for bem executado! Se o professor realmente realizar suas atribuições, que é se aproximar do aluno, que é conhecer a família, a sua infrequência, o seu rendimento, se ele fizer todas essas atribuições, que é dele. Sem dúvida todos os padrões serão alcançados... Porque a gente sabe que dentro de uma escola pública, existem ' $n$ ' fatores que vão desviando e vão te desvirtuando do seu caminho. Mas você tem que relutar sempre naquela busca, sem dúvida o projeto é uma ferramenta que auxilia sim nos desempenhos... (CPPDTEB, 2015).

Para além das atribuições explicitadas nos poucos documentos orientadores, percebe-se a responsabilização deste ator escolar pela melhoria da frequência escolar e consequentemente dos rendimentos/resultados de aprendizagem dos alunos. 
No 'contexto da estratégia política', embora o estudo não seja extensivo e não apresente os efeitos do PPDT no âmbito do Estado, este aponta para a estratégias de reorganização das práticas de gestão pedagógica e, sobretudo, para a reconfiguração da função do professor.

\section{SÍNTESE CONCLUSIVA}

Relativamente à trajetória do PPDT, nos diferentes contextos (influência, produção do texto, prática, efeitos/resultados, estratégia política) de atuação da política, observou-se que, ao nível 'meso', houve uma influência de atores locais, com expressiva atuação no campo educacional cearense e reconhecimento político.

Observou-se também que o PPDT, constituído na educação cearense, é consequência da 'interpretação da interpretação', sobre o DT existente no sistema educativo em Portugal, com esta nomenclatura, desde a década de sessenta do século passado (SÁ, 1997). Compreende-se que "a política é complexamente codificada em textos e artefatos e é decodificada (e recodificada) de forma igualmente complexa" (BALL; MAGUIRE; BRAUN, 2016, p. 14).

No nível micro, os dados revelaram que os sujeitos para os quais a política PPDT é destinada - alunos, pais, professores e gestores escolares - se mostram convencidos da importância dessa política, para a educação dos estudantes na escola cearense, ainda que se observem resistências, sobretudo quanto à sua face burocrática e a suas implicações na intensificação do trabalho docente. Contudo, tais resistências são atenuadas pelas autoridades educacionais locais, envolvidas nos grupos de interesses de mobilização, em prol da 'implantação' do PPDT.

No que se refere às aproximações e distanciamentos das significações construídas sobre o cargo/função de DT constituído no Brasil, em relação Portugal, a análise dos documentos aponta para uma possível reprodução das orientações existentes em Portugal para o exercício do cargo/função, parcialmente mediada pela interpretação que a CEP fez dessas prescrições normativas, posto que, em muitas situações, observa-se um expressivo isomorfismo textual. Para além dessa visível aproximação normativa, concluiu-se que os instrumentais (fichas biográficas, atas, formulários de registro de atendimento e ocorrência, modelos de comunicados) foram também transpostos e adotados de práticas em uso em algumas escolas portuguesas, embora, nesse caso, já não inspirados diretamente no quadro normativo português (que não explicita esses instrumentos), mas na interpretação e materialização desse quadro normativo instanciado pela investigadora portuguesa que mediou o ‘empréstimo’ dessa política educativa no 
Brasil. Como transparece dos discursos dos atores educativos entrevistados, esses instrumentais foram posteriormente objeto de recriações sucessivas de modo a adaptá-los à especificidade e às condicionantes do novo contexto da prática.

\section{REFERÊNCIAS}

AVELAR, M. Entrevista com Stephen J. Ball: uma análise de sua contribuição para a pesquisa em política educacional. Archivos Analíticos de Políticas Educativas, Arizona, v. 24, n. 24, p. 1-18, fev. 2016.

BALL, S. J.; MAGUIRE, M.; BRAUN, A. Como as escolas fazem as políticas: atuação em escolas secundárias. Tradução de Janete Bridon e Jeferson Mainardes. Ponta Grossa: Editora da UEPG, 2016.

BALL, S. J. Do modelo de gestão do "bem-estar social" ao "novo gerencialismo": mudanças discursivas sobre gestão escolar no mercado educacional. In: BALL, S. J.; MAINARDES, J. M. Políticas educacionais: questões e dilemas. São Paulo: Cortez, 2011c. p. 193-221.

Educação global S. A.: novas redes políticas e o imaginário neoliberal. Tradução de Janete Bridon e Jeferson Mainardes. Ponta Grossa: Editora da UEPG, 2014.

Educational reform: a critical and post-structural approach. Buckingham: Open University Press, 1994. 164 p. ISBN 9780335192724.

Intelectuais ou técnicos? O papel indispensável da teoria nos estudos educacionais. In: BALL, S. J.; MAINARDES, J. M. Políticas educacionais: questões e dilemas. São Paulo: Cortez, 2011b. p. 78-99.

La micropolítica de la escuela: hacia una teoría de la organización escolar. Tradução de Néstor Míguez. Madrid: Paidos, 1989. 297 p. ISBN 84-7509$529-1$.

Novos estados, nova governança e nova política educacional. In: APPLE, M. W.; BALL, S. J.; GANDIN, L. A. Sociologia da educação: análise internacional. Tradução de Cristina Monteiro. Porto Alegre: Penso, 2013. p. $177-$ 189. ISBN 9788565848244. 
. Performatividade, privatização e o pós-estado do bem-estar. Educação e Sociedade, Campinas, v. 25, n. 89, p. 1105-1026, set./dez. 2004.

- Reformar escolas/reformar professores e os terrores da performatividade. Revista Portuguesa de Educação, Braga-Portugual, v. 15, n. 2, p. 3-23, dez. 2002.

- Sociologia das políticas educacionais e pesquisa crítico-social: uma revisão pessoal das políticas educacionais e da pesquisa em política educacional. In: BALL, S. J.; MAINARDES, J. M. Políticas educacionais: questões e dilemas. São Paulo: Cortez, 2011a. p. 21-53.

BALL, S. J.; MAINARDES, J. (Orgs.). Políticas educacionais: questões e dilemas. São Paulo: Cortez, 2011.

BOWE, R.; BALL, S. J.; GOLD, A. Reforming education and changing schools: case studies in policy sociology. London: Routledge, 1992. 188 p. ISBN 0-415-07789-3.

CASTRO, E. O diretor de turma nas escolas portuguesas: o desafio de uma multiplicidade de papeis. Coleção Escolas e Saberes. Porto: Porto Editora, v. 8, 1995. ISBN 972-0-34408-3.

CHAVES, M. L. B.; LEITE, H. E. G. F. O projeto Projeto Professor Diretor de turma no Ceará, depois de dois anos. In: ENCONTRO DE POLÍTICA E ADMINISTRAÇÃO DA EDUCAÇÃO, 2009, Fortaleza. Anais... Fortaleza: [s.n.]. 2009. p. 1-11.

COSTA, D. C. A gestão do Projeto Professor Diretor de Turma: a experiência da Escola Estadual de Educação Profissional Júlio França em Bela Cruz (CE). 2014. Dissertação (Mestrado Profissional em Gestão e Avaliação da Educação Pública) - Universidade Federal de Juiz de Fora, Juiz de Fora, 2014.

LIMA, L. C. A escola como organização educativa. São Paulo: Cortez, 2001.

.A escola como organização e a participação na organização escolar: um estudo da escola secundária em Portugal (1974-1988). $2^{a}$ ed. Braga: Universidade do Minho, 1998. ISBN 972-8098-24-3. 
LIMA, V. B. de. Professor Diretor de Turma: um estudo entre Brasil e Portugal acerca de uma política educativa do estado do Ceará. 2017. 150 p. Tese (Doutorado em Educação) - Universidade Federal da Paraíba. João Pessoa, 2017. Disponível em: file:///C:/Users/Vagna/Downloads/Tese_Verso_Final_ Vagna\%20(2).pdf. Acesso em: 16 nov 2018.

MAINARDES, J.; MARCONDES, M. I. Entrevista com Stephen J. Ball: um diálogo sobre justiça social, pesquisa e política educacional. Entrevista concedida a Jefferson Mainardes e Maria Inês Marcondes. Educação e Sociedade, v. 30, n.106, jan./abr. 2009. Disponível em <http://www.cedes.unicamp.br>. Acesso em 20 de março de 2014.

MAINARDES, J. Reinterpretando os ciclos de aprendizagem. São Paulo: Cortez, 2007. 240 p. ISBN 9788524908606.

PORTUGAL. Decreto de 14 de agosto de 1895. Collecção Official da Legislação Portuguesa, Anno de 1895, Imprensa Nacional, Lisboa 1896. Disponivel em: <http://net.fd.ul.pt/legis/indice-titulos.htm>. Acesso em: 16 jan. 2016.

Decreto n ${ }^{\circ}$ 48.572. Aprova o Estatuto do Ciclo Preparatório do Ensino Secundário. Diário da República Electrónico - INCM, Secretaria Geral, Lisboa, 9 set. 1968. p. 1853. Disponivel em: <http://193.137.22.223/fotos/ editor2/1968_09_09.pdf>. Acesso em: 18 jan. 2016.

SÁ, V. Racionalidades e práticas na gestão pedagógica: o caso do director de turma. Lisboa: Instituto de Inovação Educacional, 1997. 300 p. ISBN 972-835329-4. (Colecção Ciências da Educação)

SANDER, B. Introdução à história da ANPAE como sociedade civil no campo da educação. Disponível em: < https://www.anpae.org.br/website/ documentos/estudos/estudos_01.pdf>. Acesso em: 6 de ago. 2019.

SEDUC-CE - Secretaria de Educação do Ceará. Chamada pública para adesão ao Professor Diretor de Turma, 2010. Disponível em: <http://www.seduc. ce.gov.br/index.php/ouvidoria/87-pagina-inicial-servicos/desenvolvimento-daescola/3257-diretor-de-turma>. Acesso em: 12 ago. 2017. 
STAKE, R. E. A arte da investigação com estudos de caso. $3^{\text {a }}$ ed. Lisboa: Fundação Calouste Gulbenkian, 2012. 181 p. ISBN 9789723111873.

YIN, R. K. Estudo de caso: planejamento e métodos. 4. ed. Porto Alegre: Bookman, 2010. 248 p. ISBN 9788577806553.

VAGNABRITO DE LIMA é Doutora em Educação (2017) pela Universidade Federal da Paraíba (UFPB), realizou Estágio Científico Avançado de Doutoramento pelo Programa de Doutorado Sanduíche no Exterior (PDSE-CAPES) de 1 de setembro de 2015 a 31 de agosto de 2016 na Universidade do Minho em Portugal. Mestra em Educação (2012) pela Universidade Federal de Alagoas (UFAL). Possui Especialização em Gestão Escolar (2006) pela Universidade do Estado de Santa Catarina (UDESC) e em Metodologia do Ensino Fundamental e Médio (2003) pela Universidade Estadual Vale do Acaraú (UVA). Graduada em Licenciatura Plena em História (1995). Membro do Grupo de Estudos e Pesquisa em Políticas Curriculares- GEPPC/UFPB/CNPq do Centro de Educação da Universidade Federal da Paraíba. Professora da educação básica na rede pública estadual do Ceará com experiência no ensino superior. Atualmente Coordenadora da Formação Docente e Educação a Distância da Secretaria da Educação do Estado do Ceará (SEDUC-CE). E-mail: vagna.lima@gmail.com ORCID: http://orcid.org/0000-0003-0422-1575

MARIA ZULEIDE DA COSTA PEREIRA possui graduação em Licenciatura Em Educação Física pela Universidade Estadual de Londrina (1976), graduação em Licenciatura Em Pedagogia pela Universidade Federal da Paraíba (1990), mestrado em Educação pela Universidade Federal da Paraíba (1995) e doutorado em Educação pela Universidade Metodista de Piracicaba (2001). Pós-doutorado em Educação na UERJ (2008) Atualmente é professora Titular da Universidade Federal da Paraíba atuando na graduação e pós-graduação. É lider do Grupo de Estudos e Pesquisas em Políticas Curriculares. Tem experiência na área de Educação, com ênfase em Educação, atuando principalmente nos seguintes temas: Políticas Educacionais, Políticas de currículo e suas interconexões com cultura, gênero, etc. E-mail: mzul@uol.com.br ORCID: http://orcid.org/0000-0002-8980-9302 
VIRGÍNIO ISIDRO MARTINS DE SÁ possui doutorado em Ciências da Educação, especialidade em Organização e Administração Escolar, pela Universidade do Minho (2003). Atualmente é Professor Associado no Departamento de Ciências Sociais da Educação- Instituto de Educação da Universidade do Minho. Exerce as funções de Diretor da Licenciatura em Educação e de Diretor do Departamento de Ciências Sociais da Educação. É membro integrado do Centro de Investigação em Educação (CIEd). Desenvolve a sua atividade docente nos cursos de graduação e pós-graduação (mestrado e doutoramento). É autor de diversos trabalhos académicos (livros, capítulos de livros e artigos científicos) publicados no país e no estrangeiro. Foi professor visitante na Universidade de Coimbra (Portugal) e na UFMG (Universidade Federal de Minas Gerais- Brasil) e na UNISINOS (Universidade do Vale dos Sinos- Porto Alegre- Brasil). E-mail: virsa@ie.uminho.pt

ORCID: http://orcid.org/0000-0002-1941-8664 